\title{
Disagreement between Skin Prick Tests and Specific IgE in Early Childhood
}

\author{
Amandine Chauveau ${ }^{\mathrm{a}}$ Marie-Laure Dalphin ${ }^{\mathrm{a}}$ Vincent Kaulek $^{\mathrm{c}}$ \\ Caroline Roduit ${ }^{\mathrm{e}}$ Aurore Pugin $^{\mathrm{b}}$ Erika von Mutius $^{\mathrm{f}}$ \\ Dominique Angèle Vuitton ${ }^{d}$ Jean-Charles Dalphin ${ }^{c}$
}

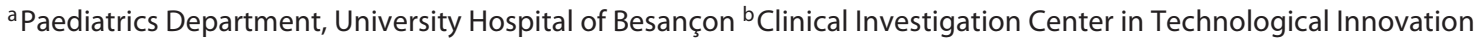
(Inserm CIC-IT 808), and 'Respiratory Diseases Department, UMR 6249 Chrono-Environnement, CNRS and University of Franche-Comté, University Hospital of Besançon, and 'EA 3181, University of Franche-Comté, Besançon, France; eChildren's Hospital, and Christine Kühne-Center for Allergy Research and Education, University of Zurich, Zurich, Switzerland; ' Dr. von Hauner Children's Hospital, Ludwig Maximilians University Munich, Munich, Germany
\end{abstract}

\section{Key Words}

Agreement - Atopic dermatitis - Childhood - Sensitization .

Skin prick test - Specific lgE

\begin{abstract}
Background: Accurate diagnosis of allergic sensitization is essential in clinical practice and allergy research, and the choice of assessment method may have an important impact. The PASTURE study (Protection against Allergy: Study of Rural Environment) examines the influence of exposure to a dairy farm environment on the occurrence of allergy in a cohort of rural European children from birth to 10 years. The aim of our study was to analyze agreement between skin prick tests (SPTs), to aeroallergens and food allergens, and specific $\lg$ E and to evaluate the association of SPT with atopic dermatitis in the 204 French children of the PASTURE study. Methods: SPT, atopic dermatitis assessment, and specific IgE measurements were performed at 1, 4.5, and 6 years. Results: A total of 137 children attended all three visits. The agreement between SPTs and specific lgE was poor except for perennial aeroallergens at 6 years and for an IgE cutoff greater than $0.7 \mathrm{lU} / \mathrm{ml}(\mathrm{k}=0.69,0.5202-0.8621)$. The prevalence of positive SPTs increased with age. Positive SPTs were transient at 1 year, whereas they were persistent between
\end{abstract}

\section{KARGER}

(c) 2016 S. Karger AG, Base

$1018-2438 / 16 / 1702-0069 \$ 39.50 / 0$

E-Mail karger@karger.com

www.karger.com/iaa
4.5 and 6 years. Positive SPTs at 1 year were predictive of the occurrence of atopic dermatitis during follow-up. Conclusion: SPTs did not have good agreement with serum-specific IgE in early childhood. Both tests (SPT and specific $\lg$ E) should be used. Skin allergenic reactivity increased with age and was transient at 1 year but associated with the occurrence of atopic dermatitis.

(c) 2016 S. Karger AG, Basel

\section{Introduction}

Although the prevalence of allergic diseases is increasing, it is important to note that common allergic-type symptoms are not always due to atopy. Therefore, an accurate diagnosis of the presence of allergy is an important public health issue [1], especially in early childhood.

In pediatric practice as in allergy research, measurement of the serum-specific IgE (SSIgE) level is generally preferred over the skin prick tests (SPT) for reasons relating to time, training in performing SPT, availability of allergen extracts, and (in some countries) safety reasons. In most studies on the occurrence of atopic dermatitis (AD) in childhood, sensitization against most common allergens is assessed by SSIgE [2].

Correspondence to: Dr. Amandine Chauveau

Paediatrics Department, University Hospital of Besançon

3 Boulevard Alexandre Fleming

FR-25030 Besançon (France)

E-Mail amandine.chauveau@free.fr 
However, it remains unclear whether SSIgE and SPT can be used interchangeably. Very few studies have compared SPT and SSIgE head-to-head, prospectively and over time, either in the general population [3] or in early childhood [4, 5].

The PASTURE study (Protection against Allergy: Study of Rural Environment) birth cohort was established to confirm the protective effect of a farming environment that was observed in previous cross-sectional studies on the development of childhood atopy and to analyze the mechanisms of protection [6]. To date, this cohort has included 1,133 families in rural areas of $5 \mathrm{Eu}-$ ropean countries (Austria, Finland, France, Germany, and Switzerland). SSIgE assays were performed in the whole cohort, whereas SPTs were performed only in the French arm. This offers a unique opportunity to determine how early allergenic sensitization in rural children was assessed by SPTs and SSIgE.

The aims of our study, which focused on children living in a rural environment, was to analyze (1) the agreement between SPTs and SSIgE and (2) the course of SPT results from 1 to 6 years and the relationship between allergic sensitization and the occurrence of $\mathrm{AD}$.

\section{Materials and Methods}

\section{Design and Study Population}

The design of the PASTURE study has previously been described in detail elsewhere [6]. The French arm of the cohort included 204 families at the third term of the mother's pregnancy in 2003. They were classed into two groups: the farmer group, comprising 95 children whose parents lived on a dairy farm and the nonfarmer group, comprising 109 children whose parents lived in the same rural areas but did not live on a farm. The inclusion and exclusion criteria were those of the overall PASTURE study [7]. Additional exclusion criteria specific to SPT were added, namely, we excluded patients with immunosuppressive or steroid therapy during the previous 2 months, antihistamine treatment within the last 7 days, and diffuse skin lesions. Data were considered noninterpretable when the 'positive' control SPT (histamine) was negative. The study was approved by the French research ethics committee (CPP), and written informed consent was obtained from all parents.

The children were seen when they were $1,4.5$, and 6 years old. SPT and SCORAD evaluation [8] were performed at each visit. Blood sampling for SSIgE measurement was performed at each visit. SPT and SSIgE measurements were performed at all three visits for 137 and 139 children, respectively. Parental history of allergy was defined as at least one parent ever having asthma, hay fever, or AD; this information was self-reported.

\section{Atopic Dermatitis}

$\mathrm{AD}$ was evaluated at each visit by the SCORAD index. We defined 'SCORAD AD' as a positive SCORAD score $(>0)$, and 'doctor's $\mathrm{AD}$ ' as $\mathrm{AD}$ diagnosed by a doctor and reported by the parents in the questionnaires between 1 and 6 years of age. The 'cumulative prevalence of $\mathrm{AD}$ ' was defined as a SCORAD $\mathrm{AD}$ at least at one visit and/or a doctor's $\mathrm{AD}$ at least once [9].

\section{Skin Prick Tests}

SPTs were performed on the anterior part of the forearm using a Stallerpoint ${ }^{\circledR}$ (Stallergenes, Antony, France). The test solution was applied as a drop with the use of a vial. Vertical pressure was applied with the Stallerpoint ${ }^{\circledR}$ followed by a 90 -degree clock-wise rotation. We used allergen extract solutions Alyostal Prick ${ }^{\circledR}$ (Stallergenes) for 13 aeroallergens (house dust mites Dermatophagoides pteronyssinus and Dermatophagoides farinae, cat, dog, Dactylis glomerata, birch pollen, grass pollen, alternaria, hazel pollen, olea, cereals, mugwort, and plantain) and 5 food allergens (hen's egg yolk, hen's egg white, cow's milk, peanut, and soybean). Reading was performed 15-20 min later by a pediatric allergist. Positive SPT was defined as a wheal diameter $\geq 3 \mathrm{~mm}$ above the negative control.

\section{SSIgE Measurements}

Blood sampling was performed according to Standard Operating Procedures of the PASTURE study. We applied a topical anesthetic EMLA ${ }^{\circledR}$ plaster (AstraZeneca, Wedel, Germany) 60 min before the blood sampling. Blood sampling was performed under sterile conditions and with the use of a venous puncture set.

SSIgE measurements were performed using the Allergy Screen Test Panel (Mediwiss Analytic, Moers, Germany). Details of this assay and its validation have previously been published [10]. Tests were performed for 13 aeroallergens (house dust mites D. pteronyssinus and $D$. farinae, cat, dog, horse, ryegrass, grass pollen, alternaria, hazel pollen, mugwort, plantain, birch pollen, and alder pollen) and 6 food allergens (hen's egg, cow's milk, hazelnut, carrot, peanut, and wheat flour).

We defined the prevalence of positive SPTs as the number of children with at least one positive SPT, and the prevalence of positive SSIgE as the number of children with at least one positive SSIgE, at any given time point.

\section{Statistical Analysis}

To analyze agreement between SPT and SSIgE, we used Cohen's kappa coefficient $(\kappa)$. Several cutoffs for the definition of 'positive SSIgE' were studied, namely 0.2, 0.35, 0.7, and $3.5 \mathrm{IU} /$ $\mathrm{ml}$. To analyze the association between positive SPTs at 1 year and positive SPTs at later time points, we used McNemar's test (Epi Info software, version 3.3.2, Atlanta, Ga., USA). To analyze the relationship between allergic sensitization and $\mathrm{AD}$, we used the $\chi^{2}$ test or Fisher's exact test, as appropriate, and we calculated the diagnostic values of SPTs for the cumulative prevalence of $\mathrm{AD}$.

\section{Results}

\section{Relationship between SPT and SSIgE}

The prevalence of positive SPTs increased with age (9.5\% at 1 year, $14.2 \%$ at 4.5 years, and $22.5 \%$ at 6 years; fig. 1a). Sensitization to food allergens decreased with age, whereas sensitization to seasonal and perennial increased 
with age. The prevalence of positive SPTs was lower in the farmer group than in the nonfarmer group at all three visits ( 8.5 vs. $10.4 \%$ at 1 year, 9.6 vs. $19.4 \%$ at 4.5 years, and 18.5 vs. $26.9 \%$ at 6 years) and for all categories of allergens, but this difference was significant only at 4.5 years for seasonal aeroallergens $(\mathrm{p}<0.05)$.

The prevalence of positive SSIgE $(>0.35 \mathrm{IU} / \mathrm{ml})$ was $41 \%$ at 1 year, $48.2 \%$ at 4.5 years, and $40.3 \%$ at 6 years (fig. 1b). Positive SSIgE to perennial aeroallergens decreased with age, whereas SSIgE to food and seasonal aeroallergens increased between 1 year and 4.5 years. There was no difference between the farmer and nonfarmer groups, regardless of the chosen cutoff. Positive SPTs and positive SSIgE $(>0.35 \mathrm{IU} / \mathrm{ml})$ by category of allergens at each visit are presented in table 1 with $p$ values showing the difference between the two methods.

The profile of allergenic sensitization, detected by SSIgE or SPT, was different, even using higher cutoffs to define positive SSIgE. Agreement between both tests was globally weak, with a poor $\kappa$-coefficient. Agreement increased with age and with higher cutoff levels for SSIgE (table 2).

\section{Course of SPT Results from 1 to 6 Years}

We observed 4 profiles of sensitization, namely persistent (positive or negative at all three visits), transient (negative at 6 years and positive earlier), incident (negative at 1 year and positive later), and intermittent (positive at least once and negative at least once).

SPTs were positive at least once during the follow-up for $30.7 \%$ of the children. Among the children with positive SPT, $7.1 \%$ had persistent, $61.9 \%$ incident, $14.3 \%$ transient, and $16.7 \%$ intermittent sensitization. Transient sensitization was only observed at 1 year and represented $75 \%$ of children with positive SPTs at 1 year. Among the children with positive SPTs at 4.5 years, $79 \%$ had persistent SPTs at 6 years. Parental history of allergy was noted for $37.5 \%$ of children with positive SPTs at 1 year versus $22.4 \%$ of children with negative SPTs at 1 year $(\mathrm{p}=0.45)$.

\section{Relationship between Allergic Sensitization and}

Occurrence of $A D$

SCORAD AD decreased with age. There was no difference between the farmer and nonfarmer groups at 1 or 4.5 years, whereas there was a nonsignificant difference $(\mathrm{p}=$ 0.18 ) between groups at 6 years (fig. 1c). The cumulative prevalence of $\mathrm{AD}$ was $46.9 \%$, and there was no difference between groups.

Disagreement between SPT and Specific $\operatorname{IgE}$

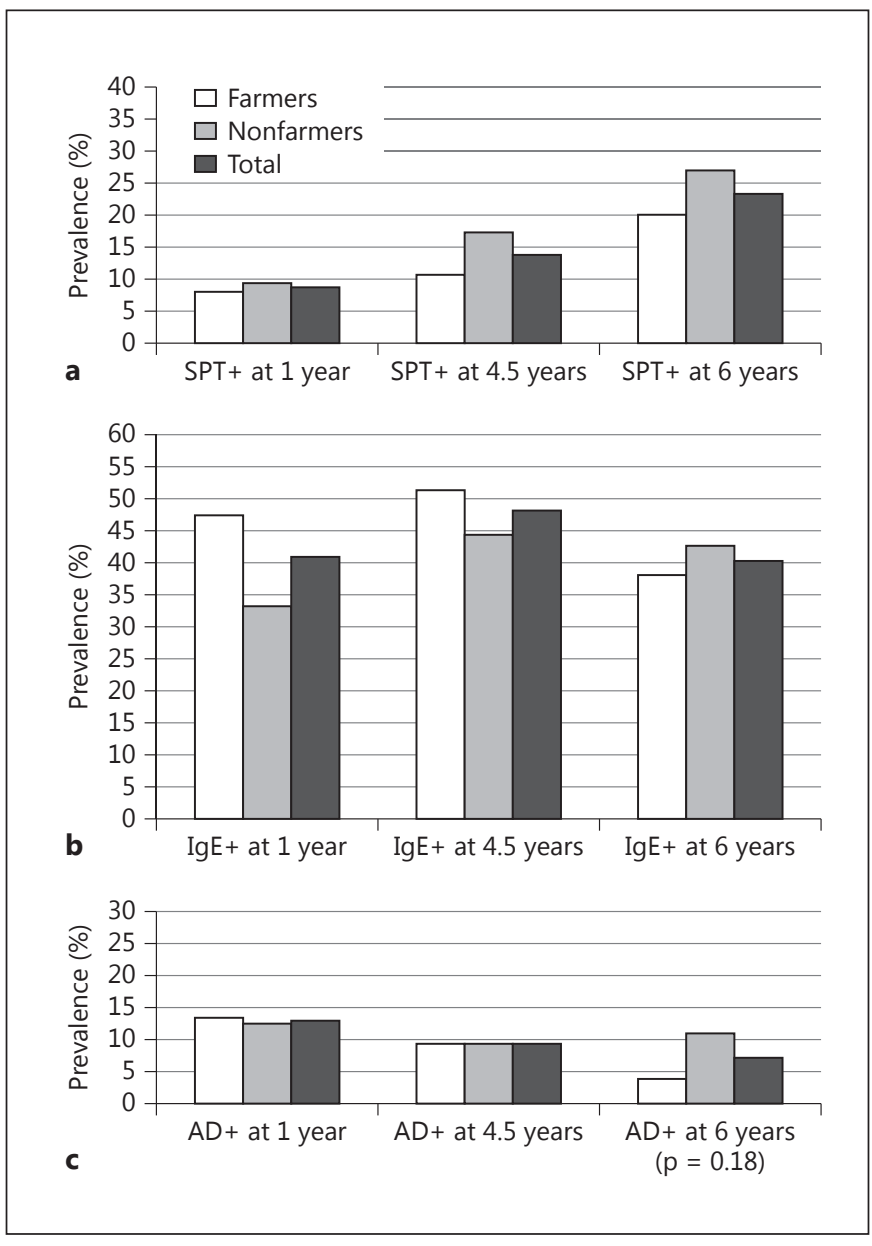

Fig. 1. Prevalence (\%) of positive SPTs (a), positive serum-specific $\mathrm{IgE}>0.35 \mathrm{IU} / \mathrm{ml}$ (b) to at least one allergen, and SCORAD-defined $\mathrm{AD}$ (c) at each visit depending on the child's status (born and living on a farm or in a nonfarming family).

There was no significant relationship between positive SPT and SCORAD AD at each time point. However, there was a significant correlation between positive SPT at 1 year and the presence and/or occurrence of $\mathrm{AD}$ during the 6 years of follow-up (specificity $96 \%$, positive predictive value $78.6 \%, \mathrm{p}=0.007$ ). Among the children who had positive SPT at 1 year and $\mathrm{AD}$ at least once during the 6 -year follow-up, $91.6 \%$ were sensitized to food allergens (83\% to egg).

In contrast, there was no significant relationship between positive SSIgE at 1 year and the presence and/or occurrence of $\mathrm{AD}(\mathrm{p}=0.12)$. The relationship was positive only when we focused on positive SSIgE to food allergens $(\mathrm{p}=0.03)$. 
Table 1. Number of positive SPTs and positive SSIgE ( $>0.35 \mathrm{IU} / \mathrm{ml})$ by category of allergen at each visit

\begin{tabular}{|c|c|c|c|c|c|c|c|c|c|c|}
\hline & & \multicolumn{3}{|l|}{1 year } & \multicolumn{3}{|l|}{4.5 years } & \multicolumn{3}{|l|}{6 years } \\
\hline & & SSIgE+ & SSIgE- & $\mathrm{p}$ & SSIgE+ & SSIgE- & $\mathrm{p}$ & SSIgE+ & SSIgE- & $\mathrm{p}$ \\
\hline \multirow[t]{2}{*}{ Seasonal aeroallergens } & $\mathrm{SPT}+$ & 0 & 0 & 0.0412 & 11 & 3 & 0.0005 & 16 & 5 & 0.1456 \\
\hline & SPT- & 6 & 154 & & 21 & 117 & & 12 & 123 & \\
\hline \multirow[t]{2}{*}{ Perennial aeroallergens } & $\mathrm{SPT}+$ & 1 & 2 & $<0.0001$ & 5 & 4 & 0.0139 & 15 & 6 & 0.1686 \\
\hline & SPT- & 56 & 101 & & 16 & 128 & & 13 & 122 & \\
\hline \multirow[t]{2}{*}{ Food allergens } & $\mathrm{SPT}+$ & 2 & 11 & 0.2652 & 0 & 1 & $<0.0001$ & 2 & 3 & $<0.0001$ \\
\hline & SPT- & 18 & 129 & & 52 & 99 & & 31 & 120 & \\
\hline \multirow[t]{2}{*}{ Any allergens } & $\mathrm{SPT}+$ & 10 & 6 & $<0.0001$ & 19 & 3 & $<0.0001$ & 28 & 8 & 0.0001 \\
\hline & SPT- & 61 & 83 & & 54 & 76 & & 34 & 86 & \\
\hline
\end{tabular}

p values obtained with McNemar's $\chi^{2}$ test.

Table 2. Values of the $\kappa$-coefficient to assess agreement between allergenic sensitization as evaluated by SPT and by SSIgE according to age at the study visit and to the IgE cutoff value

\begin{tabular}{|c|c|c|c|c|c|c|c|c|c|}
\hline & & \multicolumn{2}{|c|}{$\operatorname{IgE}>0.2 \mathrm{IU} / \mathrm{ml}$} & \multicolumn{2}{|c|}{$\mathrm{IgE}>0.35 \mathrm{IU} / \mathrm{ml}$} & \multicolumn{2}{|c|}{$\mathrm{IgE}>0.7 \mathrm{IU} / \mathrm{ml}$} & \multicolumn{2}{|c|}{$\operatorname{IgE}>3.5 \mathrm{IU} / \mathrm{ml}$} \\
\hline & & $\kappa$ & $95 \% \mathrm{CI}$ & $\kappa$ & $95 \% \mathrm{CI}$ & $\kappa$ & $95 \%$ CI & $\kappa$ & $95 \% \mathrm{CI}$ \\
\hline \multirow[t]{4}{*}{1 year } & Any allergen & 0.07 & $-0.020 ; 0.163$ & 0.08 & $-0.022 ; 0.189$ & 0.07 & $-0,059 ; 0.211$ & 0.21 & $-0,027 ; 0.453$ \\
\hline & Food allergens & 0.03 & $-0.124 ; 0.184$ & 0.02 & $-0.141 ; 0.187$ & 0.03 & $-0.143 ; 0.201$ & 0.12 & $-0.096 ; 0.343$ \\
\hline & Perennial aeroallergens & 0.05 & $-0.005 ; 0.109$ & -0.001 & $-0.058 ; 0.056$ & -0.03 & $-0.076 ; 0.003$ & -0.02 & $-0.046 ;-0.005$ \\
\hline & Seasonal aeroallergens & 0.16 & $-0.115 ; 0.429$ & 0.28 & $-0.153 ; 0.709$ & - & - & - & - \\
\hline \multirow[t]{4}{*}{4.5 years } & Any allergen & 0.17 & $0.081 ; 0.263$ & 0.23 & $0.114 ; 0.342$ & 0.34 & $0.187 ; 0.491$ & 0.37 & $0.157 ; 0.578$ \\
\hline & Food allergens & -0.13 & $-0.039 ; 0.012$ & -0.01 & $-0.038 ; 0.012$ & -0.01 & $-0.037 ; 0.012$ & -0.01 & $-0.027 ; 0.006$ \\
\hline & Perennial aeroallergens & 0.17 & $0.001 ; 0.347$ & 0.27 & $0.051 ; 0.495$ & 0.29 & $0.037 ; 0.558$ & 0.44 & $0.135 ; 0.744$ \\
\hline & Seasonal aeroallergens & 0.34 & $0.171 ; 0.516$ & 0.40 & $0.216 ; 0.587$ & 0.54 & $0.326 ; 0.750$ & 0.34 & $0.070 ; 0.611$ \\
\hline \multirow[t]{4}{*}{6 years } & Any allergen & 0.29 & $0.163 ; 0.429$ & 0.39 & $0.252 ; 0.537$ & 0.57 & $0.427 ; 0.717$ & 0.59 & $0.433 ; 0.749$ \\
\hline & Food allergens & 0.03 & $-0.069 ; 0.136$ & 0.05 & $-0.071 ; 0.176$ & 0.04 & $-0.122 ; 0.209$ & -0.02 & $-0.044 ;-0.005$ \\
\hline & Perennial aeroallergens & 0.43 & $0.266 ; 0.602$ & 0.54 & $0.361 ; 0.722$ & $0.69^{*}$ & $0.520 ; 0.862$ & 0.39 & $0.174 ; 0.625$ \\
\hline & Seasonal aeroallergens & 0.53 & $0.352 ; 0.701$ & 0.59 & $0.416 ; 0.764$ & $0.66^{*}$ & $0.493 ; 0.832$ & $0.69^{\star}$ & $0.507 ; 0.868$ \\
\hline
\end{tabular}

${ }^{*} \kappa>0.61$, indicating good agreement.

\section{Discussion}

Our study in a cohort of rural children shows that the relationship between SPT and SSIgE was very weak but increased with age and higher cutoffs, suggesting that these two tests cannot be used interchangeably to assess IgE-related allergic sensitization in early childhood. While SPT sensitization increased with age, AD prevalence decreased. The cumulative prevalence of $\mathrm{AD}$ was significantly correlated with positive SPTs at 1 year, mostly reacting to food allergens.

The comparison of both tests at three different time points in a general population of preschool children is original. The nonselected nature of the PASTURE population is unique and allows generalization of the findings. In our study, there were significantly more children with positive SSIgE than children with positive SPTs at all visits. The choice of the method for each test may have had some consequence.

Regarding the method chosen for SPT, the Stallerpoint ${ }^{\circledR}$ device was found to be less sensitive than the ALK lancet or IV needle by Masse et al. [11]. Nevertheless, the 90-degree clock-wise rotation was found to improve the sensitivity of this technique. By contrast, this technique was described by Buyuktiryaki et al. [12] as reliable, tolerable, and comparable with the ALK lancet technique. 
Regarding the method chosen for SSIgE, Wood et al. [13] showed some differences in SSIgE results according to the method of assay. However, Herzum et al. [10] found that the Allergy Screen panel yields reliable results in the detection of allergic sensitization to common allergens.

However, the higher sensitivity of SSIgE detection, previously reported in a prospective 18-month study [14], does not alone explain why the agreement between both tests was so poor in our study. The strength of agreement was only substantial [15] for aeroallergens at 6 years of age and for cutoffs of 0.7 and $3.5 \mathrm{IU} / \mathrm{ml}$. The recent meta-analysis by Soares-Weiser et al. [16] reported that very few studies have compared the tests head-to-head in the same population over time. In their populations of food-allergic subjects without age limits, SPT and SSIgE were both sensitive but not specific. In the DARC birth cohort, Kjaer et al. [17] showed that SPTs were better correlated with a diagnosis of allergic disease at 6 years than SSIgE. In a recent article on the COPSAC ${ }_{2000}$ at-risk birth cohort, Schoos et al. [5] also found a substantial disagreement between SPT and SSIgE in early childhood with all $\kappa$-coefficient under 0.60 without increasing with age.

The marked difference between the results obtained using SPT and those obtained with SSIgE is probably due to many factors. Each test can be performed by different methods [13] and influenced by various factors [18]. It has been suggested that SPT and SSIgE may be associated with specific and different atopic diseases [19], probably even more so in early life. Based on our results and on the pathophysiology of the IgE-dependent immune reactions, we fully agree with the conclusions of a Norwegian study [20] that compared SSIgE measurement and SPTs in 353 two-year old children. In this study, both tests yielded different results, were not similar in the detection of atopic sensitization, and actually reflected distinct aspects of the IgE-related immune response. Schoos et al. [5] also suggested as an explanation for the disagreement between both tests that the immune response is different in the skin and in the blood. In the review article by de Vos [21], most studies showed substantial discordance between SSIgE and skin-testing results, suggesting that the two testing methods complement each other. These authors concluded that if only one type of testing is performed, a substantial number of allergic sensitizations may be missed.

The progressive increase in the agreement between both tests in line with age is consistent with the transient and poorly explained nature of allergic sensitization to food allergens in very early childhood. However, SPTs at

Disagreement between SPT and Specific IgE
1 year, which are more related to food sensitization, are definitely associated with $\mathrm{AD}$ in the 6 first years of life, whereas SSIgE levels are not. The concomitant increase in agreement when higher cutoffs are used for SSIgE results also raises some doubts about the biological relevance of low SSIgE levels. It would also have been interesting to study various cutoffs for SPT positivity, but in our study very few children had SPT $>4 \mathrm{~mm}$, thus precluding further analysis. However, Bousquet et al. [3] showed that there was no increase in agreement between both tests with higher SPT cutoff levels.

Our study made it possible to describe the course of allergic sensitization in early childhood, as evaluated by both SPT and SSIgE in a nonselected rural population. Increased atopic sensitization with age has previously been described, but mostly in populations with risk factors for atopy $[5,22,23]$ or with atopic diseases [24], and in school-age children [25]. Few studies have addressed SPT sensitization in populations of children not selected for their predisposition to atopy. The transient nature of SPTs at 1 year has already been suggested in the Isle of Wight cohort [26], in which $80 \%$ of positive SPTs were transient at 1 year. In addition, our 6-year follow-up showed that SPTs became persistent between 4.5 and 6 years, with almost $80 \%$ persistent SPTs. This could reflect environmental exposure but also maturation of the immune system, with an age-dependent increase in capacity either to respond to or to tolerate various types of allergens. The prevalence of positive SPTs by category of allergens changed during early childhood, with food sensitization predominant at 1 year and decreasing thereafter, whereas aeroallergen sensitization was low at 1 year and subsequently increased. Similar findings were observed by Rhodes et al. [23] in a birth cohort with family atopy.

Our study suggests that SPT sensitization at 1 year, albeit transient, is associated with the presence and occurrence of $\mathrm{AD}$. Most positive SPTs at 1 year in children who had AD during follow-up were directed against food allergens, especially egg allergens, as previously reported by van Asperen et al. [27]. The role of sensitization to food allergens in $\mathrm{AD}$ has been suggested by several studies in children with $\mathrm{AD}[28,29]$, and the course of $\mathrm{AD}$ has been reported to be significantly related to the presence of SSIgE to egg [30]. Few studies have focused on the prediction of $\mathrm{AD}$ by early sensitization to food allergens, as assessed by SSIgE, and even less so by SPT. In the DARC birth cohort [17], the early presence of food SSIgE was a highly significant predictor of allergic diseases at 6 years, especially for $\mathrm{AD}$, whereas children sensitized early to in-

Int Arch Allergy Immunol 2016;170:69-74 DOI: $10.1159 / 000446776$ 
halant allergens had no increased risk of allergic disease at 6 years. The overall evaluation of SSIgE in the entire PASTURE cohort at 1 year showed an interesting correlation with maternal atopy [31], which might thus be the real cause of the link between food-related IgE antibodies and $\mathrm{AD}$. However, in our subgroup from the PASTURE study, the extremely poor agreement between $\mathrm{AD}$ and SSIgE detected at 1 year and the absence of a statistically significant correlation between parental history of allergy and positive SPT at 1 year render this hypothesis highly unlikely. Although the pathophysiological meaning of the predictive value of early sensitization to egg allergens for $\mathrm{AD}$ occurrence remains obscure, this finding could be used to select at-risk children for closer follow-up in order to detect any further development of atopic diseases and/or for interventional studies in the future.

\section{References}

1 Holgate ST, Lack G: Improving the management of atopic disease. Arch Dis Child 2005; 90:826-831.

2 Asarnoj A, Ostblom E, Kull I, Lilja G, Pershagen G, Hedlin G, et al: Sensitization to inhalant allergens between 4 and 8 years of age is a dynamic process: results from the BAMSE birth cohort. Clin Exp Allergy 2008;38:15071513.

3 Bousquet P-J, Chatzi L, Jarvis D, Burney P: Assessing skin prick tests reliability in ECRHS-I. Allergy 2008;63:341-346.

4 Kjaer HF, Eller E, Høst A, Andersen KE, Bindslev-Jensen C: The prevalence of allergic diseases in an unselected group of 6-year-old children. The DARC birth cohort study. Pediatr Allergy Immunol 2008;19:737-745.

5 Schoos A-MM, Chawes BLK, Følsgaard NV, Samandari N, Bønnelykke K, Bisgaard H: Disagreement between skin prick test and specific IgE in young children. Allergy 2015;70: 41-48.

6 Mutius E, Schmid S; The PASTURE project: EU support for the improvement of knowledge about risk factors and preventive factors for atopy in Europe. Allergy 2006;61:407413.

7 Pfefferle PI, Büchele G, Blümer N, Roponen M, Ege MJ, Krauss-Etschmann S, et al: Cord blood cytokines are modulated by maternal farming activities and consumption of farm dairy products during pregnancy: the PASTURE Study. J Allergy Clin Immunol 2010; 125:108-115.e1-3.

8 Severity scoring of atopic dermatitis: the SCORAD index. Consensus Report of the European Task Force on Atopic Dermatitis. Dermatology 1993;186:23-31.

9 Roduit C, Frei R, Loss G, Büchele G, Weber J, Depner M, et al: Development of atopic dermatitis according to age of onset and association with early-life exposures. J Allergy Clin Immunol 2012;130:130-136.e5.

10 Herzum I, Blümer N, Kersten W, Renz H: Diagnostic and analytical performance of a screening panel for allergy. Clin Chem Lab Med 2005;43:963-966.
11 Masse MS, Granger Vallée A, Chiriac A, Dhivert-Donnadieu H, Bousquet-Rouanet L, Bousquet P-J, et al: Comparison of five techniques of skin prick tests used routinely in Europe. Allergy 2011;66:1415-1419.

12 Buyuktiryaki B, Sahiner UM, Karabulut E, Cavkaytar O, Tuncer A, Sekerel BE: Optimizing the use of a skin prick test device on children. Int Arch Allergy Immunol 2013;162: 65-70.

13 Wood RA, Segall N, Ahlstedt S, Williams PB: Accuracy of IgE antibody laboratory results. Ann Allergy Asthma Immunol 2007;99:3441.

14 Jøhnke H, Norberg LA, Vach W, Høst A, Andersen KE: Patterns of sensitization in infants and its relation to atopic dermatitis. Pediatr Allergy Immunol 2006;17:591-600.

15 Landis JR, Koch GG: The measurement of observer agreement for categorical data. Biometrics 1977;33:159-174.

16 Soares-Weiser K, Takwoingi Y, Panesar SS, Muraro A, Werfel T, Hoffmann-Sommergruber $\mathrm{K}$, et al: The diagnosis of food allergy: a systematic review and meta-analysis. Allergy 2014;69:76-86.

17 Kjaer HF, Eller E, Andersen KE, Høst A, Bindslev-Jensen C: The association between early sensitization patterns and subsequent allergic disease. The DARC birth cohort study. Pediatr Allergy Immunol 2009;20:726734.

18 Baldacci S, Omenaas E, Oryszczyn MP: Allergy markers in respiratory epidemiology. Eur Respir J 2001;17:773-790.

19 Tollerud DJ, O'Connor GT, Sparrow D, Weiss ST: Asthma, hay fever, and phlegm production associated with distinct patterns of allergy skin test reactivity, eosinophilia, and serum IgE levels. The Normative Aging Study. Am Rev Respir Dis 1991;144:776-781.

$20 \mathrm{R} \varnothing \mathrm{AD}$, Saunes M, Smidesang I, Storrø O, Oien T, Moen T, et al: Agreement of specific $\mathrm{IgE}$ and skin prick test in an unselected cohort of two-year-old children. Eur J Pediatr 2012; 171:479-484.

21 de Vos G: Skin testing versus serum-specific IgE testing: which is better for diagnosing aeroallergen sensitization and predicting clinical allergy? Curr Allergy Asthma Rep 2014;14:430.
22 Ege MJ, Frei R, Bieli C, Schram-Bijkerk D, Waser M, Benz MR, et al: Not all farming environments protect against the development of asthma and wheeze in children. J Allergy Clin Immunol 2007;119:1140-1147.

23 Rhodes HL, Thomas P, Sporik R, Holgate ST, Cogswell JJ: A birth cohort study of subjects at risk of atopy. Twenty-two-year follow-up of wheeze and atopic status. Am J Respir Crit Care Med 2002;165:176-180.

24 Johnston SL, Clough JB, Pattemore PK, Smith S, Holgate ST: Longitudinal changes in skinprick test reactivity over 2 years in a population of schoolchildren with respiratory symptoms. Clin Exp Allergy 1992;22:948-957.

25 von Mutius E, Martinez FD, Fritzsch C, Nicolai T, Reitmeir P, Thiemann HH: Skin test reactivity and number of siblings. BMJ 1994; 308:692-695.

26 Dean T, Venter C, Pereira B, Arshad SH, Grundy J, Clayton CB, et al: Patterns of sensitization to food and aeroallergens in the first 3 years of life. J Allergy Clin Immunol 2007; 120:1166-1171.

27 van Asperen PP, Kemp AS: The natural history of IgE sensitisation and atopic disease in early childhood. Acta Paediatr Scand 1989;78: 239-245.

28 Sampson HA, McCaskill CC: Food hypersensitivity and atopic dermatitis: evaluation of 113 patients. J Pediatr 1985;107:669-675.

29 García C, El-Qutob D, Martorell A, Febrer I, Rodríguez M, Cerdá JC, et al: Sensitization in early age to food allergens in children with atopic dermatitis. Allergol Immunopathol 2007;35:15-20.

30 Ricci G, Patrizi A, Baldi E, Menna G, Tabanelli M, Masi M: Long-term follow-up of atopic dermatitis: retrospective analysis of related risk factors and association with concomitant allergic diseases. J Am Acad Dermatol 2006; 55:765-771.

31 Depner M, Ege MJ, Genuneit J, Pekkanen J, Roponen M, Hirvonen M-R, et al: Atopic sensitization in the first year of life. J Allergy Clin Immunol 2013;131:781-788.

Chauveau/Dalphin/Kaulek/Roduit/Pugin/ von Mutius/Vuitton/Dalphin 